\title{
PROPUESTA DE UN MODELO DE LA INTELIGENCIA EMOCIONAL APLICADO A LA EXPERIENCIA DE LA LECTURA EN CONTEXTO ESCOLAR
}

\section{PROPOSAL OF AN EMOTIONAL INTELLIGENCE MODEL APPLIED TO THE READING EXPERIENCE IN SCHOLAR CONTEXTS}

http://dx.doi.org/10.15304/ie.28.5290

\author{
Rocío G-Pedreira \\ CIEC, Instituto de Educação-Universidade do Minho \\ Instituto de Ciencias da Educación-Universidade de Santiago de Compostela \\ rociopedreira@outlook.es
}

\section{RESUMEN}

La consideración de la dimensión emocional de la lectura en las planificaciones docentes forma parte de una de las innovaciones educativas más importantes en el ámbito de la didáctica de la lengua y la literatura. No obstante, todavía es un campo inexplorado y con pocas concreciones teóricas que organicen los aspectos de la educación emocional implicados. El presente trabajo ofrece una propuesta de modelo mixto de la inteligencia emocional aplicado a la experiencia de la lectura en contexto escolar que explica las fases del proceso de mediación docente y las destrezas de las que depende la relación afectiva y efectiva de los agentes emocionales implicados: el mediador, el lector, la obra y el grupo de iguales. En el marco teórico se realiza una revisión de los principales modelos de inteligencia emocional propuestos por distintos expertos en la materia aplicados al ámbito empresarial y, en menor medida, al educativo, que parten de la revolucionaria teoría de las inteligencias múltiples de Howard Gardner (1983) y el concepto de inteligencia emocional de Salovey y Mayer (1990).

Palabras clave: Inteligencia, emoción, literatura, educación, modelo, mediador, lectura, hábito.

\begin{abstract}
The consideration of the reading emotional dimension in teacher plannings is one of the most important educational innovations in the field of Language and Literature Didactics. Nevertheless, it is still an unexplored field and with few theoretical concretions which organize the emotional education aspects involved in the reading experience. This study offers a proposal of a mixed emotional intelligence model applied to reading experience in scholar context which explains the mediation process steps and the necessary skills of which the affective and effective emotional agent's relationship depends: the mediator, the reader, the book and the peer group. The theoretical framework reviews the principal models of emotional intelligence proposed by different experts in the field applied to the business and, to a lesser extent, the education, which assume the revolutionary theory of multiple intelligences of Howard Gardner (1983) and the concept of emotional intelligence of Salovey and Mayer (1990).

Keywords: Intelligence, emotion, literature, education, model, mediator, reading, habit.
\end{abstract}




\section{INTRODUCCIÓN}

La consideración explícita de la dimensión emocional del aprendizaje es una de las propuestas innovadoras con más éxito en la actualidad que se aplica a la totalidad de aprendizajes realizados en el contexto escolar. No obstante, su integración en la planificación de la mediación lectora realizada por los docentes es un terreno poco evaluado a nivel teórico y con escasos estudios que sustenten su validez. Las emociones estéticas son las emociones producidas por las obras de arte, entre ellas las literarias, y no han sido de especial interés en campos como la historia del arte o los estudios sobre la inteligencia puesto que, a nivel práctico, su existencia es muy próxima a las emociones ordinarias (Bisquerra, 2009). Sin embargo, la capacidad de las lecturas literarias de producir emociones es lo que las convierte en experiencias equiparables a las propias vivencias humanas y, por tanto, decisivas en la construcción de la identidad personal y de la persona como ser social, especialmente en un período tan susceptible a los estímulos externos como la infancia y la juventud. Además, la atención a la dimensión emocional de la experiencia de la lectura en contexto escolar es posible gracias al abandono de las corrientes historicistas de la didáctica de la lengua y la literatura que valoraban el conocimiento sobre el patrimonio literario por encima de todo, hasta llegar a la actualidad, donde el principal interés es la relación emocional del texto y el lector y el papel activo y protagónico que el receptor tiene en la dotación de significado de la lectura.

El objetivo principal de este artículo es ofrecer un posible modelo de inteligencia emocional aplicable a la experiencia de la lectura en contexto escolar que, a diferencia de las lecturas personales, implica a otros agentes emocionales como son el mediador o el grupo de iguales. Por tanto, a partir de los principales modelos que partieron, entre otras, de la teoría de las inteligencias múltiples de Gardner (1983), se propone un modelo mixto de habilidades organizadas en función a una secuenciación por fases de la lectura que abarca desde la planificación docente previa hasta la reflexión posterior.

\section{SOBRE EMOCIÓN, INTELIGENCIA EMOCIONAL Y SUS PRINCIPALES MODELOS}

La emoción se define como un estado complejo del organismo que empieza por una excitación o perturbación que desencadena una respuesta organizada o, en otras palabras, la reacción a un acontecimiento externo o interno. Dicho acontecimiento también recibe el nombre de estímulo u objeto (un hecho, una cosa, un animal, persona, etc.). Bisquerra $(2003,2009)$ explica que la emoción se produce a partir de informaciones sensoriales que llegan a los centros emocionales del cerebro que conllevan una respuesta neurofisiológica cuya información interpreta el neocórtex. Por tanto, podemos hablar de tres componentes implicados en la emoción:

- Neurofisiológico: respuestas involuntarias que el sujeto no controla, pero que sí pueden ser prevenidas a través de la relajación.

- Comportamental (o expresión emocional): elementos no verbales que permiten la identificación de las emociones que se están experimentando, como las expresiones faciales, el tono de voz, volumen, etc. La regulación de la expresión emocional se relaciona con la maduración y afecta positivamente al establecimiento de relaciones sociales. 
- Cognitivo (o experiencia emocional): sería la sensación consciente de la emoción, también denominada sentimiento, que permite calificar y darle nombre a un estado emocional.

La importancia del conocimiento y regulación adecuada de las emociones radica en su influencia en el comportamiento y acciones del individuo, que puede optar por enfrentarse o huir de las situaciones a las que se enfrenta. Por ejemplo, la agresividad es una reacción a una emoción normalmente negativa, como el miedo o la ira, pero las mismas emociones pueden ser correctamente reguladas y transformarse en autocontrol. Todo depende de la eficiencia en su gestión.

Aunque no hay consenso sobre si existen y cuales son las emociones primarias, en ocasiones se habla de entre cinco o siete familias de emociones claramente identificables que engloban una gran cantidad de emociones secundarias: (emociones negativas) la ira, el miedo, la tristeza, la aversión, (emociones positivas) la alegría, el amor, (emociones neutras o ambiguas) la sorpresa, y el interés. Estas emociones se interrelacionan para dar a su vez emociones complejas e inmensurables debido a los incontables matices y reacciones de la personalidad humana.

La competencia emocional forma parte de las competencias socio-emocionales que tienen como objetivo la autorreflexión, la empatía y la eficacia en la expresión y regulación de las emociones y, en consecuencia, el manejo de las reacciones. Las personas que consiguen llevar a cabo estos procedimientos son emocionalmente inteligentes, capaces de entender las emociones y los sentimientos de uno mismo y de los demás y de utilizar la información que proporcionan para modificar el pensamiento y las propias acciones. La gran influencia que tienen las emociones en la cognición, los procesos racionales y la conducta, determina que lo emocional deba formar parte también del currículum escolar y de las programaciones docentes de un modo explícito.

La formulación inicial del concepto de inteligencia emocional parte de Salovey y Mayer (1990), que no recibió demasiada atención hasta que fue reinterpretado y difundido por Goleman (1995). No obstante, su origen fue posible gracias a la revolución que significó la teoría de las inteligencias múltiples de Howard Gardner (1983), que planteaba la existencia de siete inteligencias (a las que después él mismo añadió dos más) en contra de la concepción clásica y reduccionista que defendía la existencia de una sola inteligencia, estable a lo largo de la vida y medible mediante pruebas objetivas. Las inteligencias propuestas por Gardner son las siguientes (a partir de la traducción realizada en 2005 por Esther Rodríguez Quintana con la autorización del autor y publicada en la Revista de Psicología y Educación):

- Lingüística: dominio y amor por el lenguaje y las palabras y su exploración; propia de escritores o lingüistas.

- Lógico-matemática: facilidad al confrontar y evaluar objetos y abstracciones, discernir sus relaciones y aspectos subyacentes; propia de matemáticos o científicos.

- Musical: competencia para componer e interpretar piezas con entonación, ritmo y timbre y/o escuchar, disfrutar y juzgar la música; propia de compositores o músicos.

- Espacial: habilidad para percibir el mundo visual, transformarlo y modificarlo; propia de arquitectos, artistas o cartógrafos. 
- Corporal-cinestética: controlar y ejecutar movimientos corporales y manejar objetos con precisión; propia de atletas, bailarines o actores.

- Inteligencias (intra o inter) personales: determinar estados de ánimo, sentimientos y otros estados en uno mismo (intrapersonal) y en los demás (interpersonal), utilizando la información para guiar el comportamiento; propia de psicólogos, políticos o antropólogos.

- Naturalista: reconocer y categorizar objetos naturales; propia de biólogos y naturalistas.

- Existencial: captar y debatir cuestiones de la existencia; propia de filósofos o líderes espirituales.

En su exposición inicial, Gardner no confirmaba la existencia de esta última inteligencia debido a la falta de pruebas que, respondiendo a los criterios que él mismo había establecido para determinar una inteligencia, confirmaran su autenticidad. Sin embargo, también planteó la posibilidad de la existencia de otras. En efecto, la gran cantidad de posibles inteligencias fue uno de los aspectos más criticados de su teoría hasta la actualidad, argumentando que muchas de ellas se solapaban y que las inteligencias interpersonal e intrapersonal difícilmente podrían ser aceptadas en el mundo académico por falta de apoyo empírico. No obstante, el propio Gardner explica que aunque algunos psicólogos se mostraron escépticos sobre su teoría, muchos educadores la aceptaron, puesto que "encaja en sus intuiciones de que los niños son inteligentes de formas distintas", al mismo tiempo que "alberga la esperanza de ayudar a más estudiantes de modo más efectivo si sus formas preferidas de pensar son tenidas en cuenta en el currículo, en la instrucción y en la evaluación” (Gardner, 2005, p. 21). La inteligencia se entiende ahora como un colectivo de taxonomías de la inteligencia que están presentes en cada individuo en distinta medida, y que determina su manera de enfrentarse al proceso educativo.

En 1988, Sternberg presenta su teoría triárquica de la inteligencia, la cual concibe la existencia de tres distintas: la analítica, la creativa y la práctica. Según el autor, la inteligencia es toda actividad mental que ayude en la adaptación consciente del entorno, de modo que la inteligencia académica, la más clásica de todas, no es una inteligencia exitosa obligatoriamente. El autor define las tres inteligencias del siguiente modo:

- Inteligencia analítica (o componencial): capacidad de análisis, evaluación, juicio, comparación y contraste de la información.

- Inteligencia creativa (o experiencial): habilidad de aprender a partir de la experiencia y dar respuestas acertadas y únicas a nuevos problemas.

- Inteligencia práctica (o contextual): capacidad de aplicar los componentes de la inteligencia para adaptarse y enfrentarse a los problemas que surjan, a través de la selección y manipulación del ambiente y lo que lo integra.

Por otra parte, para entender el origen del término de inteligencia emocional es necesario hacer referencia a la inteligencia social, concepto introducido por Thorndike en 1920. La inteligencia social implica la capacidad de integrar pensamientos, sentimientos y comportamientos en las 
relaciones sociales para que sean satisfactorias y positivas, tanto a nivel personal (con respecto a uno mismo) como colectivo (con respecto a los demás) (Thorndike y Stein, 1937).

Después de analizar algunos de los antecedentes en materia de inteligencia, ahora hablaremos de las principales formulaciones con respecto a la emoción. Como indica Bisquerra (2009, p. 120), las inteligencias que más interesan en el estudio de la inteligencia emocional son la intra e inter personal. La simbiosis de las dos origina la inteligencia emocional en el modelo de Goleman. Los modelos de la inteligencia emocional se dividen en modelos de habilidades, que se fundamentan en la existencia de habilidades cognitivas para el procesamiento de la información emocional; modelos mixtos, que incluyen rasgos de personalidad como el control del impulso, la motivación, la tolerancia a la frustración, el manejo del estrés, la ansiedad, la asertividad o la confianza; y otros modelos que incluyen componentes de personalidad, habilidades cognitivas y otros factores que, en algunos casos, se crearon explícitamente para el propio modelo con el objetivo de enfatizar el sentido popular y divulgativo de la inteligencia emocional (García-Fernández y Giménez-Mas, 2010).

La propuesta de Salovey y Mayer (1990, p. 189) categoriza la inteligencia emocional como una subcategoría de la inteligencia social que engloba "the ability to monitor one's own and others' feelings and emotions, to discriminate among them and to use this information to guide one's thinking and actions". Se trata de un modelo de habilidades de la inteligencia emocional que incluye los siguientes procesos mentales:

- Evaluación y percepción de las emociones propias y de otros.

- Regulación de las emociones propias y de otros.

- Utilización de las emociones.

Posteriormente, los mismos autores publican un estudio sobre las implicaciones educativas del desarrollo y la inteligencia emocional (1997) donde proponen una estructura de cuatro ramas de habilidades involucradas en la inteligencia emocional organizadas de más simples a más complejas, conscientes de que se va desarrollando con la edad y la experiencia. Las cuatro ramas son la regulación reflexiva de las emociones para la promoción del crecimiento emocional e intelectual, el entendimiento y análisis de las emociones para el uso activo del conocimiento emocional, la facilitación emocional del pensamiento y la percepción, identificación y expresión de las emociones.

Como ya se ha adelantado, la propuesta de Salovey y Mayer no tiene mucha difusión hasta la publicación de Emotional Intelligence de Daniel Goleman (1995), cuyo modelo mixto actualiza años más tarde (1998, p. 196). Parte de la teoría de los dos autores anteriores para realizar un modelo de inteligencia emocional aplicable al mundo laboral que incluye la autoconciencia, la autorregulación, la automotivación, la empatía y las habilidades sociales.

La tesis presentada en 1983 por Bar-On adelantó el concepto introducido por Salovey Y Mayer aunque no recibió mucha atención hasta diez años después cuando reformuló su propuesta inicial y creó el inventario de medida EQ-I. Su modelo mixto está compuesto por varios componentes que a su vez integran distintos aspectos: 
- Componente intrapersonal (comprensión emocional de sí mismo, asertividad, autoconcepto, autorrealización, independencia).

- Componente interpersonal (empatía, relaciones interpersonales satisfactorias, responsabilidad social).

- Componente de adaptabilidad (solución de problemas, prueba de la realidad, flexibilidad).

- Componentes del manejo del estrés (tolerancia al estrés, control de los impulsos).

- Componente del estado de ánimo (felicidad, optimismo).

Dentro da la multitud de modelos que quedan fuera de estas dos primeras categorizaciones y recogidos por García-Fernández y Giménez-Mas (2010), destacan el modelo de los "Cuatro Pilares" de Cooper y Sawaf (1997), desarrollado principalmente en el ámbito empresarial, que incluye la alfabetización emocional, la agilidad emocional, la profundidad emocional y la alquimia emocional; el modelo de Boccardo, Sasia y Fontela (1999) que se caracteriza por diferenciar la inteligencia emocional (autoconocimiento emocional, control emocional y automotivación) de la inteligencia interpersonal (reconocimiento de las emociones ajenas y habilidad para las relaciones interpersonales); o el modelo de Rovira (1998), que por primera vez ofrece subdimensiones del concepto para la mejora de su medición.

Otro modelo interesante desarrollado más recientemente es el que propone Bisquerra (2003, 2009), que se centra en el contexto educativo. El autor define el concepto de competencias emocionales como "el conjunto de conocimientos, capacidades, habilidades y actitudes necesarias para tomar conciencia, comprender, expresar y regular de forma apropiada los fenómenos emocionales" (2009, p. 146), y establece un pentágono de competencias emocionales que incluye:

- La conciencia emocional: tomar conciencia de las propias emociones, darles nombre, comprender las de los demás y tomar conciencia de la interacción entre emoción, cognición y comportamiento.

- La regulación emocional: expresar las emociones de manera apropiada, regular las emociones y sentimientos, desarrollar habilidades para afrontar retos y situaciones de conflicto generadas por las emociones y la competencia para autogenerar emociones positivas.

- Autonomía emocional: desarrollar la autoestima, la capacidad de automotivación, la autoeficacia emocional o, en otras palabras, la percepción de ser eficaz en las relaciones sociales, la responsabilidad que permite responder por los propios actos, la actitud positiva, el análisis crítico de las normas sociales, mensajes culturales y de los medios de comunicación de masas y la resiliencia, o capacidad de enfrentarse con éxito a condiciones de vida adversas.

- Competencia social: dominar las habilidades sociales básicas, respetar a los demás, practicar la comunicación receptiva, siendo capaz de entender los mensajes provenientes de la comunicación verbal y no verbal, practicar la comunicación expresiva, compartir las emociones, el comportamiento prosocial y la cooperación, es decir, la capacidad de ayudar a los demás sin la necesidad de que soliciten la ayuda, la asertividad, la prevención y solución de conflictos y la capacidad para gestionar situaciones emocionales. 
- Competencia para la vida y el bienestar: fijar objetivos adaptativos, tomar decisiones, buscar ayuda y recursos, ciudadanía activa, participativa, crítica, responsable y comprometida, la capacidad de gozar conscientemente del bienestar emocionar y la habilidad de dejarse fluir.

Otro concepto fundamental para la temática de este estudio introducido por Bisquerra en su obra Psicopedagogía de las emociones (2009) es el concepto de emoción estética, del que ya hablamos en la introducción del estudio. El autor explica que las emociones estéticas son las que se experimentan ante cualquier obra de arte, también literaria o cinematográfica. Algunos autores afirman que las obras de arte lo que producen son emociones ordinarias, pero que no implican nuevos conceptos, lo que puede explicar su poco estudio y consideración. No obstante, aunque en muchos campos como la historia del arte o el estudio de la inteligencia la diferencia entre las emociones ordinarias y las producidas por las obras de arte no se considera relevante, son muy importantes en el ámbito de la educación formal y la educación literaria.

\section{LA DIMENSIÓN EMOCIONAL DE LA EXPERIENCIA DE LA LECTURA}

El objetivo de los docentes es la prevención de situaciones conflictivas a partir de la gestión de las emociones estéticas producidas por obras ficcionales. Por otro lado, la terapia o trabajo directo sobre las emociones ordinarias es asunto de los profesionales de la psicología y campos afines y parte de la realidad vivencial del sujeto, inmerso en una situación peligrosa para su integridad física o mental, aunque sea necesaria la implicación y participación de toda la comunidad educativa en la respuesta ofrecida. Es decir, los docentes trabajamos temas como la discriminación a partir de la literatura cuyas historias sean sensibles o extrapolables a situaciones discriminatorias y la manera de enfrentarlas, pero debemos acudir a un orientador o persona capacitada para intervenir en un caso de discriminación activo en nuestra aula para el que debemos partir de la realidad de la víctima. Por ejemplo, a la hora de tratar el tema del bullying o acoso escolar con nuestro alumnado se pueden utilizar libros como El club de los raros (2015), de Jordi Sierra i Fabra, o la situación inicial del pequeño mago Potter antes de descubrir su naturaleza mágica en Harry Potter and the Philosopher's Stone (1998) de J. K. Rowling. Ambos libros presentan situaciones sobre las que se puede hablar o reflexionar, intentando ofrecer herramientas para evitar y prevenir la aparición de los elementos o factores desencadenantes del abuso. No obstante, si existe un caso de acoso en nuestra aula, el procedimiento de acción debe ser mucho más inmediato y controlado, priorizando la rapidez de la eliminación del peligro y de posibles efectos adversos. Sería también el caso de obras sobre la muerte o la guerra, temáticas especialmente sensibles por su dureza, pero de necesario tratamiento en el aula. Según Leibrandt (2013),

enfocar el estudio de las emociones y de la identidad a través de la LIJ y buscar un fin pedagógico se hace especialmente atractivo a través de las posibilidades de identificación que conectan directamente con el mundo de las experiencias particulares de cada uno de los pequeños y grandes lectores. Las lecturas permiten un alto grado de identificación si se relacionan con lo conocido personalmente por el lector; así, reafirman sus ideas y experiencias y, posiblemente, refuerzan sus convicciones. Por otro 
lado, conducirán a reflexionar sobre nuevas experiencias que puedan contradecir o parecer irreconciliables con el propio mundo de vivencias (p. 150).

Por tanto, la literatura se convierte en el principal recurso utilizado en las programaciones para el desarrollo de la inteligencia emocional. No obstante, se debe respetar y tener en cuenta que la instrumentalización de la literatura juega en contra de la adquisición del hábito lector y niega una de las dimensiones básicas de la obra literaria, la dimensión estética. Como destacan importantes investigadores de LIJ y educación literaria en al ámbito nacional (Roig Rechou, 2013; Cerrillo Torremocha, 2001, 2010, entre otros), son obras, ante todo, literarias, y dirigidas, en primera instancia, a un lector infantil, juvenil y a los mediadores de lectura, pero también a cualquier otro tipo de lector.

Sanjuán Álvarez, en el libro La dimensión emocional en la educación literaria (2013) engloba todo el marco teórico y resultados obtenidos durante la realización de su tesis doctoral sobre la temática que también abarca en otras publicaciones $(2011,2014,2015,2016)$, y defiende las tres dimensiones o funciones de la literatura que, en esencia, sería una reinterpretación de los tres ejes constituyentes de la Literatura Infantil y Juvenil:

- La ética: la literatura como vía de acceso al conocimiento del mundo y de uno mismo.

- La estética: la literatura a través de una construcción estética que conmueve, como espejo de la realidad.

- La liberadora: la literatura como alternativa a la realidad a través de una representación nueva y creativa que, aunque desde el distanciamiento, sirve como vía de percepción y conocimiento de la propia realidad.

La autora sustenta su investigación en la afirmación de que el componente emocional es intrínseco al acto de lectura y que sin la implicación emocional no es posible la interpretación. Define la lectura como una experiencia para la que es necesario que el lector tenga "disposición a la comunicación”. La relación entre el texto literario y el lector (2013):

pone en juego todo lo que el lector es no solo sus habilidades cognitivas como lector, sino todo lo que podríamos denominar como su intertexto vital: sus experiencias personales, sus miedos, sus deseos, su capacidad de imaginar, sus recuerdos..., y todo ello a través de un uso peculiar del lenguaje que pretende, sobre todo, afectarle y llegarle a lo más íntimo. Para que se dé esta peculiar comunicación entre el libro literario y el lector, este debe estar dispuesto a emprender esa transformación que el texto puede ejercer en su visión del mundo, en su sentido de la realidad, en sus valores (p. 108).

Otras de las ideas que la autora destaca es la relación directa de tres de las inteligencias propuestas por Gardner con la educación literaria: la inteligencia existencial y su intento de dar respuesta a las preguntas sobre el sentido de la vida, una función inherente a la literatura desde sus inicios; la inteligencia interpersonal y la capacidad de la literatura de mostrar situaciones que le ayuden en la resolución de conflictos y el análisis social a través de la observación de realidades ficcionales en las que se sumerge el lector a nivel psicológico; y la inteligencia intrapersonal, a través del poder de la literatura de influir en la construcción de la propia identidad y el desarrollo 
de mecanismos de introspección. Sanjuán Álvarez recuerda que la dimensión emocional del aprendizaje es relevante en cualquier situación de aprendizaje, pero también de una manera especial en el aprendizaje lector y literario a través de una doble relación mutua: el papel de las emociones del lector en el aprendizaje literario y el papel de la literatura en la construcción de la identidad personal y el desarrollo integral de los individuos. Además, el análisis de la dimensión emocional de la experiencia de lectura tiene un doble foco de interés: cómo la lectura afecta al lector en sus facetas vitales, afectivas, estéticas y éticas y de qué manera las características emocionales y socioculturales del lector interactúan con el texto para dotarlo de sentido.

La formación literaria necesita del conocimiento y el aprendizaje de saberes teóricos que potencien la valoración y el disfrute, pero no constituyen, en esencia, su finalidad. Es necesaria la transmisión de conocimientos que permitan vivir la lectura e integrarla en la experiencia personal. En palabas de Mendoza Fillola (2004, p. 77), “el tratamiento didáctico de la literatura procura que la aproximación para aprender a valorar, a apreciar y a interpretar las creaciones de signo estéticoliterario se haga a través de la propia actividad y la experiencia personal". Como ya ha sido señalado, la literatura cuenta con tres dimensiones diferenciadas: la estética, propia de toda obra de arte; la ética, por su capacidad de inducir y modificar comportamientos, actitudes y conceptos con respecto al sistema de valores; y la emocional, por su capacidad de producir emociones en el lector. En el caso de la Literatura Infantil y Juvenil, la especificidad del receptor implica que la dimensión ética se amplíe a un concepto más cognitivo y de aprendizaje, puesto que el lector se encuentra en uno de los momentos más susceptibles y en pleno proceso madurativo, sensible a los estímulos que recibe y su integración en la construcción de su personalidad y el entendimiento del mundo; por otra parte, también varía parcialmente la dimensión emocional con la aparición de la figura del mediador, cuya intervención es determinante para la posibilidad de acceso a las obras literarias por parte de los jóvenes lectores.

\section{PROPUESTA DE MODELO DE INTELIGENCIA EMOCIONAL}

La propuesta de un modelo de la inteligencia emocional aplicado a la experiencia de lectura responde a la necesidad de reconocer la existencia de cuatro sujetos emocionales: el mediador de lectura, la obra (haciendo referencia al escritor o a los propios personajes), el lector y el grupo de iguales. Utilizamos el término "sujeto emocional" para hacer referencia a los sujetos (individuos o colectivos) receptores o productores de emociones implicados en el proceso de lectura que no están presentes en las lecturas personales de un modo tan directo. El proceso de lectura en base a su dimensión emocional se ha dividido en cuatro fases:

- Fase 1: preparación. Actividad previa e independiente del profesorado que debe realizar fuera de clase y del período lectivo que corresponde a la preparación de la sesión. Implica la necesaria lectura de las obras que se van a proponer y de la vivencia emocional de dichas lecturas, con el objetivo de seleccionar y planificar las posibilidades que tienen al aplicarlas en el contexto concreto del aula, teniendo en cuenta las particularidades de cada lector o alumno. Los agentes emocionales implicados son el mediador y la propia obra. 
- Fase 2: implementación o pre-lectura. Se desarrolla en contexto aula y ya está presente el principal receptor de la propuesta, el lector-alumno. En este caso también puede ser un lector colectivo si la programación está planificada por grupos o con el grupo completo. Sería la fase de motivación o fomento lector que predispone positivamente a los receptores a la lectura potencial de un texto. En este caso tenemos tres agentes implicados, el mediador, la obra y el lector.

- Fase 3: resultado o lectura. Se ha decidido optar por el término resultado para destacar la importancia que la lectura directa de la obra debe tener en la educación literaria. Todas las actividades previas o posteriores a este momento tienen el objetivo de conseguir que la experiencia de la lectura se realice de manera efectiva, con la exploración simultánea de las tres dimensiones o funciones de la literatura (ética, estética y liberadora). En este caso, los agentes implicados son el lector y la obra, aunque el mediador siga estando de alguna manera presente en un segundo plano.

- Fase 4: reflexión o post-lectura. La última, pero no menos importante, consiste en facilitar momentos de reflexión donde los lectores puedan compartir las emociones experimentadas durante la lectura con su grupo de iguales, de manera libre, recordando que las interpretaciones deben ser un acto individual y no preestablecido. Cada lector vive y experimenta la lectura de manera distinta, conectándola con su intertexto lector y vital, de modo que las interpretaciones o valoraciones con respecto a la obra también van a ser únicas e irrepetibles.

Como es posible ver en el siguiente cuadro (Figura 1), el sujeto constante durante toda la actividad es la propia obra de lectura que, al mismo tiempo, es el único sujeto pasivo durante el proceso. La obra siempre va a ser la misma, pero cambia el sujeto activo con el que entra en contacto $y$, por tanto, la gestión emocional es realizada por el mediador en primera instancia, luego por el lector y, por último, por el grupo de iguales.

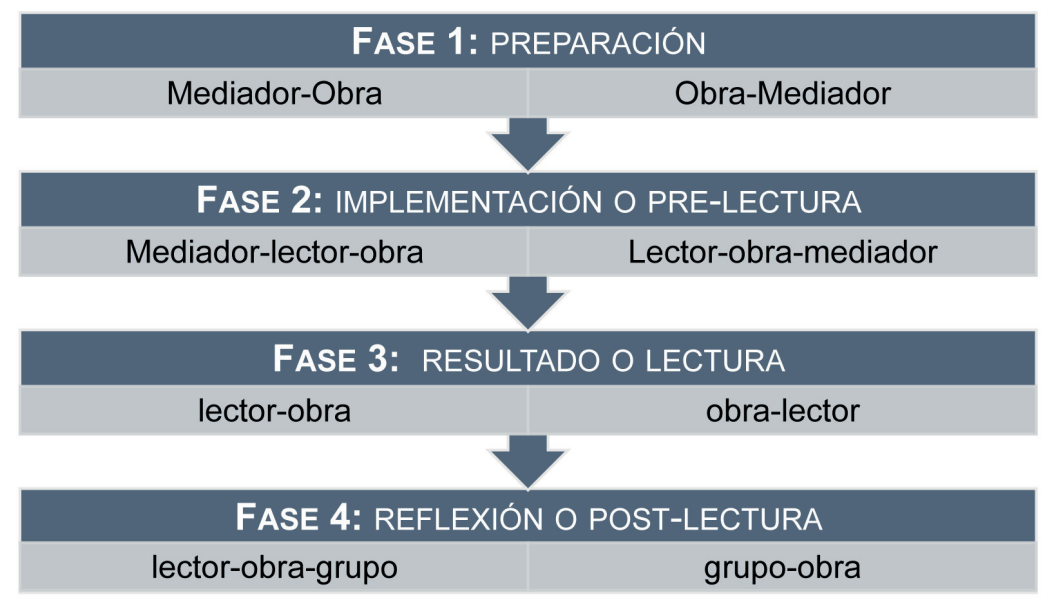

Figura 1. Los agentes emocionales en la experiencia de la lectura. 
Los componentes de la inteligencia emocional del modelo aplicados al sujeto que inicia o toma la iniciativa en la actividad serían:

- El mediador con respecto a la obra:

- Responsabilidad: toda actividad docente debe tener en cuenta que se trabaja con individuos sociales y afectivos en el momento más sensible de su evolución madurativa, donde los estímulos recibidos son fundamentales para la creación de su autoconcepto y la concreción de su personalidad y modelo de valores. Por tanto, el mediador debe ser capaz de entender las consecuencias que pueden acarrear sus acciones, tanto positivas como negativas.

- Conciencia y regulación emocional propia: reconocer y regular las propias emociones para así poder mostrarse empático a las emociones que experimentarán sus alumnos cuando vivan la misma experiencia de lectura, pero desde un estadio evolutivo distinto

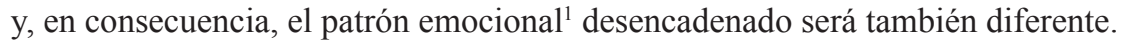

- Automotivación: gestionar las emociones de modo que se mantenga el espíritu de búsqueda y predisposición hacia las lecturas potenciales del aula. No todo lo que se lee será adecuado para el contexto aula y formar parte del canon formativo, lo que complica y aumenta el tiempo dedicado a la fase de preparación. La desmotivación del profesorado, acrecentada por la falta de recursos, formación y capacidad de reacción ante los problemas que pueden surgir, es uno de los mayores problemas para el colectivo. La superación de este estado improductivo debe realizarse a nivel personal, no esperando una motivación externa por parte de la comunidad o la propia sociedad que, posiblemente, nunca vaya a llegar.

- Flexibilidad: habilidad para adaptar la gestión emocional producida por el contacto con la obra literaria cualquiera que sea la temática o la modalidad genérica propuesta, teniendo en cuenta que la función del mediador es guiar y promover la lectura del lector implícito, que no tiene por qué compartir gustos ni intereses y, por supuesto, tampoco comparten las mismas referencias en su intertexto lector.

- Adaptabilidad: capacidad para adaptarse al entorno, sus condicionantes y oportunidades de reinterpretación libre, tanto en lo respectivo a las imposiciones legislativas, como de recursos o la propia idiosincrasia de su alumnado, de una manera constructiva y positiva, gestionando y redirigiendo la negatividad o la frustración que muchas veces sufre el docente.

En esta propuesta se ha decidido introducir el concepto de patrón emocional para hacer referencia a la evolución de emociones que se viven durante la experiencia de la lectura. No es posible explicar la vivencia emocional que supone la lectura con una sola emoción o con un colectivo de emociones interrelacionadas, sino que la evolución y cambio de emociones tan opuestas como el miedo o la ira y la felicidad es uno de las posibilidades más enriquecedoras de la literatura. En efecto, es una experiencia que imita la evolución emocional producida por las vivencias propias, presentes incluso antes y después de la lectura. No obstante, el patrón emocional con respecto a la obra literaria hace referencia a los cambios que se producen desde el inicio de la lectura hasta su final, sin querer en ningún momento restar importancia a los demás. 
- El mediador con respecto al lector:

- Empatía: capacidad de ponerse en el lugar de otra persona (en este caso el lectoralumno) y sentir, comprender y apreciar sus emociones en base a su momento evolutivo y contexto personal.

- Asertividad: habilidad para expresar los sentimientos, pensamientos y creencias propias sin dañar o cohibir a los demás a través de un contacto no destructivo. La educación tradicional se asentaba sobre la acentuada relación jerárquica del docente y su alumnado, lo cual dificultaba la implicación activa de los más jóvenes en el proceso de enseñanzaaprendizaje. No obstante, solo el docente que entiende que el verdadero protagonista del aprendizaje es el alumno y que se debe partir de sus conocimientos previos, apreciando el valor y las características propias de la infancia como un elemento positivo y enriquecedor podrá llegar a establecer nexos de unión entre la actividad realizada dentro de la institución escolar y el contexto social fuera de sus límites.

- Anticipación: capacidad de anticipar y prepararse para los cambios no planificados que se hacen necesarios ante una respuesta emocional imprevista del alumnado o el fracaso (parcial) de los objetivos propuestos para la programación docente. Además, también entraría en este aspecto la habilidad para estar preparado para alterar o adaptar una acción en función de algún cambio o evento relevante en la vida de nuestros alumnos o el propio contexto social. Las catástrofes naturales, conflictos bélicos y otros sucesos alarmantes deben ser explorados también en el contexto aula para paliar los efectos negativos que desencadenan en todo individuo inmerso en la realidad social. La literatura se destaca como el mejor recurso posible para esta tarea.

- Conciencia y regulación emocional externa: con el lector en el centro del proceso, el mediador debe ser capaz de identificar y gestionar las emociones del lector y así conseguir motivarlo hacia la obra propuesta. En muchos casos, la motivación fue mal interpretada creyendo que debía partir de los propios alumnos y de lo que para ellos resultaba interesante o atractivo. No obstante, la labor del docente consiste precisamente en planificar la educación literaria de manera que la lectura termine por ser una inquietud y necesidad para todos los alumnos, los que se autodefinen como lectores y los que no.

- Persuasión: habilidad para influir en los comportamientos de los demás, muy relacionada con lo expuesto en el apartado anterior. El buen docente debe ser capaz de dirigir a los alumnos desde un control no explícito. Por ejemplo, en el caso de la educación literaria está patente cuando un mediador ofrece una selección de lecturas comprobadas y analizadas de manera previa, para que el alumno tome una decisión libre sobre cual elegir, aunque en una semi-libertad determinada por el criterio del docente.

- El lector con respecto a la obra:

- Conciencia y regulación emocional propia: una vez que el mediador pasa a un segundo plano, el lector debe ser capaz de reconocer y regular las emociones provocadas por la experiencia de lectura, tanto si responde a las provocadas por la involucración inconsciente del lector dentro de la ficción creada del escritor como un partícipe externo o a través de la identificación con un personaje de la ficción y la sincronización de sus estados emocionales. Aunque en un primer momento la presencia de personajes 
próximos al desarrollo y procesamiento psicológico de los más jóvenes es un requisito fundamental para la adecuada inmersión en la realidad de la ficción y la activación de la función liberadora de la literatura, la maduración del alumno como lector le permite poder experimentar la lectura en su máximo exponente con obras que, en apariencia, no le resultan totalmente accesibles o próximas.

- Empatía: en este caso hace referencia a la capacidad de sentir, comprender y apreciar las emociones estéticas que vivimos en nombre de los personajes de la ficción o las que nos produce la intencionalidad emocional de conexión que todo autor se propone al escribir y publicar un libro. Toda obra, durante su realización, es algo personal e íntimo, una parte del propio creador que lanza al mundo cargada de emociones, vivencias y referencias, para que otros lectores externos la hagan suya y la vuelvan a vivir a partir de su realidad.

- Autoconcepto: capacidad para comprender, aceptar, respetar y valorar positivamente a uno mismo, teniendo en cuenta tanto las limitaciones como posibilidades de cada persona. Las concepciones erróneas del autoconcepto, tanto hacia una vertiente excesiva (autoestima demasiado alta) como pobre (baja autoestima) deriva en una dificultad hacia el aprendizaje y la consecución de metas objetivamente alcanzables.

- Autorrealización: a través de una correcta construcción del autoconcepto, la autorrealización haría referencia a la habilidad para alcanzar las metas que nos proponemos, que están dentro de nuestro alcance que deseamos y, por tanto, disfrutamos. La evolución del hábito lector pasa de una lectura realizada por condicionantes externos (el refuerzo de los mediadores docentes, familiares, sociales y otro tipo de premios motivadores) a una lectura que se realiza por la propia consideración que se tiene de la lectura, a través de una interiorización de las posibilidades y recompensas que tiene la propia experiencia para la persona.

- Independencia: capacidad para dirigir las propias acciones, sentirse seguro y confiando en su realización y ser independientes a nivel emocional. Sería el objetivo básico de la educación literaria dentro de la institución escolar: crear lectores autónomos que tengan la lectura inserida en sus prácticas diarias y su tiempo personal de ocio.

- El lector con respecto al grupo de iguales:

- Conciencia y regulación emocional (propia y externa): en este caso, la confrontación con el grupo de iguales y la importancia que tiene la aceptación y valoración positiva del individuo por parte de sus compañeros, hace necesario que el alumno identifique y gestiona sus propias emociones con respecto al grupo y las del grupo con respecto a uno mismo, para poder actuar a favor de una construcción de grupo que beneficie a todos sus integrantes. El docente debe seguir estando presente en este punto y, de hecho, su presencia y supervisión es fundamental. Es necesario que identifique las dificultades que puede haber en el proceso de socialización entre los iguales y prevenir actitudes o situaciones violentas $\mathrm{y} / \mathrm{o}$ discriminatorias.

- Asertividad: como sucede en todo contacto social, es necesario que toda interacción se produzca en un contexto emocional libre pero respetuoso, donde toda aportación o reflexión crítica es lícita siempre que se realice sin dañar o atentar contra los derechos y el bienestar de otra persona. 
- Responsabilidad social: habilidad de mostrarse receptivo en el contacto con el grupo de iguales, cooperar con ellos y aportar constructivamente, identificándolos como compañeros de clase, pero también amigos y miembros de su comunidad.

- Persuasión: capacidad de inducir en los compañeros del grupo de iguales, íntimamente relacionada con la competencia de aprender a aprender. La participación activa y protagónica en el proceso de aprendizaje es beneficiosa para el alumno que la lleva a cabo y para los compañeros que la comparten, al romper con la visión estereotipada de la función y rol del profesor y del alumno en un sentido tradicional.

-Capacidad de relación: habilidad de aplicar todos los recursos a nivel emocional disponibles para relacionarse, establecer y mantener relaciones satisfactorias y cercanas emocionalmente que vuelven a nuestros alumnos más sensibles e intolerantes con las situaciones discriminatorias que pueden vivir sus compañeros.

\section{CONCLUSIÓN}

El modelo propuesto es una aproximación teórica a la inclusión efectiva de la dimensión emocional en las planificaciones sobre lectura literaria en contexto escolar. Las visiones historicistas de la didáctica de la lengua y de la literatura adquieren un papel secundario en la actualidad ante la alarma social de la multitud de problemáticas presentes en nuestro contexto y la falta de recursos de los individuos para poder enfrentarse a ellos de una manera constructiva.

La lectura, interpretada como un contacto emocional con las historias y personajes de la ficción, se convierte en una experiencia productora de emociones estéticas equiparables a las ordinarias, y un recurso idóneo para el trabajo preventivo de muchos problemas contemporáneos ya citados. No obstante, la correcta interpretación de la función de la literatura en la construcción de la personalidad de los más jóvenes, la conciencia crítica y la capacidad empática, parte de la consideración de las obras literarias en su triple dimensión (ética, estética y emocional) y del trabajo para la interiorización del hábito lector. Dentro de la escuela se trabaja la lectura con el objetivo de conseguir lectores literarios sensibles a sus realidades y a la realidad de la ficción que acudan a los libros en su tiempo libre y por iniciativa propia. Pasan de ser lectores dependientes de los estímulos externos a lectores por necesidades intrínsecas a ellos mismos.

Las fases del modelo, los agentes emocionales implicados y las habilidades emocionales necesarias para su éxito son una propuesta no definitiva, susceptible de cambios a tenor de estudios empíricos que proporcionen datos para la reinterpretación del modelo pero que, en todo caso, se basan en la realidad (o expectativa) de las actuales planificaciones de la educación literaria y la labor del mediador-docente.

\section{REFERENCIAS}

Bar-On, R. (1983). The development of an operational concept of psychological well-being. Unpublished doctoral dissertation. Rhodes University, South Africa. 
Bisquerra, R. (2003). Educación emocional y competencias básicas para la vida. Revista de Investigación Educativa, 21(1), 7-43. Recuperado de http://revistas.um.es/rie/article/view/99071

Bisquerra, R. (2009). Psicopedagogía de las emociones. Madrid: Editorial Síntesis.

Cerrillo Torremocha, P. (2001). Lo literario y lo infantil: concepto y caracterización de la Literatura Infantil. En P. Cerrillo y J. García Padrino, La literatura infantil en el siglo XXI (pp. 79-94). Cuenca: Ediciones de la Universidad de Castilla-La Mancha.

Cerrillo Torremocha, P. (2010). Literatura Infantil y Juvenil y educación Literaria. Barcelona: Ediciones Octaedro, S.L.

García-Fernández, M. y Giménez-Mas, S.I. (2010). La inteligencia emocional y sus principales modelos: propuesta de un modelo integrador. Espiral. Cuadernos del Profesorado, 3(6), 43-52. DOI: https://doi.org/10.25115/ecp.v3i6.909

Gardner, H. (1983). Frames of mind. The theory of multiple intelligences. Nueva York: Basic Books.

Gardner, H. (1993). Multiple intelligences: The theory in practice. Nueva York: Basic Books.

Gardner, H. (2005). Inteligencias múltiples. Revista de Psicología y Educación, 1(1), 17-26. Recuperado de http://www.revistadepsicologiayeducacion.es/pdf/2.pdf

Goleman, D. (1995). Emotional intelligence: Why it can matter more than IQ. Nueva York: Bantam Books.

Goleman, D. (1998). La práctica de la inteligencia emocional. Barcelona: Kairós.

Leibrandt, I. (2013). Fomentar la competencia emocional a través de la LIJ. SEDLL. Lenguaje y textos, 38, 149-158. Recuperado de http://www.sedll.org/es/revista-lenguaje-textos

Mayer, J. y Salovey, P. (1997). What is emotional intelligence? En P. Salovey y D. J. Sluyter (eds.), Emotional development and emotional intelligence (pp. 3-31). Nueva York: Basic Books.

Mendoza Fillola, A. (2004). La educación literaria: bases para la formación de la competencia lecto-literaria. Málaga: Ediciones Aljibe.

Roig Rechou, B. A. (2013). Educación Literaria e Literatura Infantil e Xuvenil. Porto: Tropelias \& Companhia.

Salovey, P. y Mayer, J. D. (1990). Emotional Intelligence. Imagination, Cognition, and Personality, 9, 185-211. DOI: https://doi.org/10.2190/DUGG-P24E-52WK-6CDG

Sanjuán, M. (2011). De la experiencia de la lectura a la educación literatura. Análisis de los componentes emocionales de la lectura literaria en la infancia y la adolescencia. Ocnos, 7, 85-100. DOI: http://dx.doi.org/10.18239/ocnos_2011.07.07

Sanjuán, M. (2013). La dimensión emocional en la educación literaria. Zaragoza: Prensas de la Universidad de Zaragoza.

Sanjuán, M. (2014). Leer para sentir. La dimensión emocional de la educación literaria. Impossibilia, 8, 155-178. Recuperado de http://ojs.impossibilia.org/index.php/impossibilia/article/ view/105

Sanjuán, M. (2015). Leer, sentir, pensar, ser: educación literaria y libertad del lector infantil y juvenil. En R. Jiménez y M. F. Romero coords.), Nuevas líneas de investigación e innovación en educación literaria (pp. 63-74). Barcelona: Octaedro.

Sanjuán, M. (2016). Los factores emocionales en el aprendizaje literario. En J. L. Soler, L. Aparicio, O. Díaz, E. Escolano y A. Rodríguez (coords.), Inteligencia Emocional y Bienestar II. 
Reflexiones, experiencias profesionales e investigaciones (pp. 156-171). Zaragoza: Ediciones Universidad San Jorge. Recuperado de https://dialnet.unirioja.es/descarga/libro/655308.pdf. Sternberg, R. J. (1988). The triarchic mind: A new Theory of human intelligence. Nueva York: Penguin.

Thorndike, E. L. y Stein, S. (1937). An evaluation of the atemps to mesure social intelligence. Psychological Bulletin, 34(5), 275-285. DOI: http://dx.doi.org/10.1037/h0053850 